\title{
Angústia: essencial e contingente O Yoga e a Psiconeuroimunologia
}

Durante centenas de milhares de anos, o destino do homem confundiu-se com o do seu grupo, da sua tribo, fora da qual ele não podia sobreviver. A tribo, por seu turno, também não podia sobreviver e defender-se a não ser pela coesão. Daí o extremo poder subjectivo das leis que organizavam e garantiam essa coesão. Determinado indivíduo, por vezes, talvez pudesse infringi-las, mas nenhum, sem dúvida, teria sonhado negá-las. Dada a enorme importância selectiva que, necessariamente, tais estruturas sociais assumiram, $e$ durante tanto tempo, é dificil deixar de pensar no quanto devem ter influenciado a evolução genética das categorias inatas do cérebro humano. Esta evolução devia não só facilitar a aceitação da lei tribal, mas também criar a necessidade da explicação mítica que a justificasse, conferindo-lhe soberania. Somos os descendentes desses homens. Foi deles, sem dúvida, que herdámos a exisgência de uma explicação, a angústia que nos impele na busca do sentido da existência. Angústia criadora de todos os mitos, de todas as religiões, de todas as filosofias e da própria ciência.

Jacques Monod, "O Acaso e a Necessidade»

A crise cultural, de valores e de criatividade, implantada nos tempos correntes, reflecte-se na filosofia, na arte, na ciência e no comportamento social. A fragmentação do conhecimento conduziu à especialização e competitividade excessivas características da sociedade individualista pós-moderna. A época tecnológica que atravessamos gerou o Homo Psychologicus - no dizer de Gilles Lipovetscky em "A Era do Vazio" - cujo destino é a autonomia e a independência, sem capacidade para sonhar.

Henri Bergson, em "A Evolução Criadora», considera que o desenvolvimento da inteligência racional no Homo Sapiens provocou um grave e lamentável enfraquecimento dos poderes intuitivos. Erwin Schrödinger comparou a Mecânica Quântica ao Vedanta, texto sagrado hindu. Niels Bohr utilizou o símbolo Tao chinês no brasão associado ao título de nobreza dinamarquês que lhe foi atribuido pela sua valiosa contribuição científica. Louis De Broglie afirmou que não devemos esquecer quanto os nossos conhecimentos são limitados e de que imprevistas evoluções são susceptíveis. Os casos citados constituem exemplos de excepção na procura da unidade dos fenómenos físico-químicos, biológicos ou mesmo psíquicos e da interrelação entre ciência, arte e filosofia e as grandes tradiçōes espirituais da humanidade.

Verifica-se, actualmente, um grande interesse na divulgação dos designados «estados avançados de consciên- cia», como seja o interessante estudo de Louis Pauwels e Jacques Bergier em "O Despertar dos Mágicos», e da utilização da sugestão hipnótica sobre o subconsciente de Richard Shames e Chuck Sterin em «Healing with Mind Power", e de Joseph Murphy em "The Power of your Subconscious Mind", livros considerados best-sellers mundiais.

Edgar Morin, em «As Grandes Questōes do Nosso Tempo", afirma que a razão enlouquece quando se fecha sobre si mesma, que um racionalismo excessivo só vê embustes nos fenómenos psi (relacionados com percepçð̃es extra-sensoriais), mas que um espírito aberto admite a possibilidade da sua existência como uma nova explicação racional. Considera, por exemplo, que a alucinação, fenómeno durante muito tempo associado à loucura, se admite hoje capaz de acompanhar situações de angústia e êxtase.

Aldous Huxley, em "O Céu e o Inferno", analisa o efeito semelhante à hipnose provocado pelos alucinogéneos mescalina e ácido lisérgico que actuam no espírito conduzindo-o a elevados níveis de consciência. Como consequência do fascínio inerente às suas próprias experiências com estas drogas, Huxley introduziu-as mesmo na sua obra de ficção. Assim, no "Admirável Mundo Novo" inventou o "soma» que, não tendo efeitos secundários nocivos à saúde, controla os cidadãos em benefício do estado e, em "A Ilha», o "mosksha», provocador de visőes e de aumento de poder de consciência numa sociedade utópica sem ambições de poder.

As experiências com alucinogéneos nem sempre, porém, são inofensivas. Jean-Paul Sartre descreve em "Os Sequestrados de Altona" as visões aterrorizadoras que durante largos meses o perseguiram. Sartre interessou-se, no seu estudo filosófico'sobre a imaginação, pelo sonho, pelas imagens hipnagógicas e pelas anomalias da percepção. Tomou mescalina para observar o fenómeno alucinatório em si próprio e passou a ver os objectos horrorosamente deformados, receando mesmo ter adquirido uma psicose alucinatória crónica que conduziria necessariamente à loucura.

Para combater desequilíbrios psicossomáticos, utilizam-se tranquilizantes e anti-depressivos. John Postgate, professor e investigador na Universidade de Sussex, defende no seu livro "Os Micróbios e o Homem» que a descoberta de fármacos de origem microbiana poderá tornar a estrutura social e o seu comportamento mais racionais. 
Contudo, apesar dos avanços científicos no domínio da Bioquimica, pouco se sabe sobre as possibilidades da prevenção e cura das doenças e, em particular, sobre os mecanismos cerebrais de controlo hormonal e é preocupante, hoje em dia, a dependência medicamentosa, especialmente nos países desenvolvidos.

Tem-se admitido que o sistema nervoso central controla apenas as percepçðes sensoriais, sendo as funçðes vitais do nosso organismo controladas pelo sistema nervoso simpático que actua igualmente sobre as glândulas endócrinas tiróide, paratiróides, timo, pâncreas, supra-renais, sexuais e, em particular, sobre a hipófise, situada na base do cérebro, cujas hormonas são reguladoras da secreção hormonal das outras glândulas.

As hormonas interferem em muitas funçס̄es a nível da célula, cujo metabolismo é constituído por um conjunto de reacçð̃es catabólicas e anabólicas. As exigências energéticas da célula são satisfeitas principalmente pela decomposição da glucose. O glicogénio, polímero da glucose, é armazenado nos músculos e no fígado e destina-se a ser usado rapidamente como fonte energética estabilizando o nível de glícidos no sangue.

As células têm elevada concentração de ião potássio e baixa de sódio. As modificaçð̃es no potencial da membrana celular, rápidas e pontuais de tal modo que a célula tem uma diferença de potencial constante, são conseguidas à custa dos níveis destes iões. Este mecanismo está na base da excitabilidade dos nervos e das contracçð̄es musculares.

Uma das hormonas mais importantes é a adrenalina, produzida pelas supra-renais, de acção instantânea no organismo. Provoca alteração no metabolismo da glucose e é destruída por oxidação, especialmente nos músculos.

A adrenalina constitui uma defesa natural do organismo a situaçð̃es de perigo, estando associada ao sentimento de medo. Como resposta ao rubor ou palidez instantâneos, à secura de boca e aperto no estâmago, dá-se uma aceleração cardíaca, o sistema nervoso é estimulado e os reflexos aumentam, gerando-se euforia $\mathrm{e}$ até insensibilidade à dor. $\mathrm{O}$ sangue enriquece-se de acetilcolina que intensifica o consumo de oxigénio nas células. Tanto a acetilcolina como o ácido glutâmico existente no cérebro são substâncias transmissoras de impulsos nervosos. Pensa-se que o efeito alucinogénico das drogas mescalina e ácido lisérgico é devido a amino-grupos do mesmo tipo do ácido glutâmico, contidos nestes estimulantes, e que o efeito soporífico de drogas depressivas se baseia no aumento de acetilcolina que provoca ondas cerebrais lentas.

O stress, situação de medo ou fadiga prolongada, pode, no entanto, provocar perturbaçð̄es no sono, no funcionamento digestivo e intestinal e ainda ocasionar cefaleias, sintomas depressivos, estado de choque, hipertensão, e doenças cardíacas, entre outras. Sob situação de stress modifica-se a sensibilidade da membrana celular ao cálcio que, actuando no exterior da célula, impede trocas dos iőes sódio e potássio influenciando o metabolismo da produção de acetilcolina, com as consequências já referidas. $\mathrm{O}$ disfuncionamento digestivo e intestinal e dos mecanismos termo-reguladores, pode ser explicado pela interferência do stress na produção de serotonina, substância vasoconstritora existente no cérebro e no intestino.

A hipertensão é devida à formação de noradrenalina e dopamina nas células nervosas. A adrenalina e a nora- drenalina estão implicadas na deposição de colesterol nas paredes internas das artérias e no aumento da viscosidade do sangue.

A hipertensão prolongada pode ter como consequência a arteriosclerose: quando a hipertensão se instala, a batida cardíaca normaliza-se e modifica-se a resistência ao fluxo sanguíneo. As artérias vão perdendo elasticidade, enrigecem e ficam estaladiças. O colesterol, ao depositar-se, evita os derrames mas a diminuição do diâmetro interior das artérias provoca aumentos locais de pressão sanguínea com o risco de deslocação de placas que, passando à circulação, podem vir a afectar veias do coração ou do cérebro, com consequências fatais.

O Yoga pratica-se na Índia há mais de cinco mil anos, tendo-se propagado inicialmente por tradição oral. Os textos mais antigos tiveram origem após a invasão ariana, cerca de 1500 anos a.C. Os sutras, aforismos concisos escritos em sânscrito (língua sagrada dos brâmanes) por Pátañjali, três séculos antes de Cristo, constituem o mais importante e divulgado texto clássico sobre Yoga. De entre eles, transcrevem-se quatro que se consideraram significativos no que respeita ao equilíbrio da mente:

\section{योगशिचत्तवृत्तिनिरोषः।}

\section{O Yoga é o controlo das funções mentais}

\section{दु:खदोमंनस्यांगपेजयत्वशवासप्रशवासा विक्षेपसहभुव:}

Os sintomas da tispersão mental são o sofrimento, $o$ desespero, o nervosismo e a respiração irregular

\section{मैत्रीकरुएामुदितोपेक्षाणां सुखदुःखपुण्यापुण्यविषयाणां- भावनातरिचत्तप्रसादनम् ।}

A serenidade da mente é obtida mediante o cultivo da amizade, compaixão, alegria e indiferença, respectivamente aos que são felizes, infelizes, bons e maus

\section{श्रुतानुमानप्रज्ञाम्यामन्य विषया विशेषार्थंत्वात् ।}

O conhecimento obtido pela dedução e pelo testemunho verbal não se compara com o que é alcançado nos estados superiores de consciência

O Yoga, uma filosofia holística de vida, tem como objectivo o controlo do corpo e do espírito através da regularidade da prática de exercício físico, descontracção muscular e mental. Provoca efeitos de relaxação capazes de alterar o comportamento e conduzir a elevados estados de consciência.

Os exercícios respiratórios e vocais do Yoga constituem uma excelente prática para oxigenar o sangue e regularizar a circulação. As vibrações originadas pela repeti- 
ção continuada de sons, por exemplo, provocam modificações no fluxo sanguíneo: a uma inspiração rápida e profunda segue-se uma expiração prolongada, acompanhada de contracção regular dos músculos abdominais com consequente elevação do diafragma.

As técnicas do Yoga conduzem a alteraçð̃es de atitudes mentais que se repercutem no sistema nervoso simpático, regulando não só a circulação sanguínea como também as glândulas endócrinas e os órgãos vitais do corpo.

Análises hormonais realizadas em indivíduos em stress, antes e depois de alguns meses de Yoga, mostraram claramente os benefícios desta prática.

Escolas piloto que introduziram técnicas de relaxação de alguns minutos diários obtiveram nos estudantes desenvolvimento da capacidade de reflexão, intuição e auto-controlo.

A meditação também já foi introduzida na vida pública, com sessð̃es regulares na Organização das Naçð̃es Unidas, no Congresso dos Estados Unidos da América e no Parlamento inglês.

Através das novas terapias que utilizam exercícios físi$\cos$ e respiratórios e imobilidade absoluta, com relaxação física e concentração mental, podem curar-se insónias, cefaleias, hiperdependência medicamentosa, depressões nervosas, úlceras, colites e hipertensão. Mais controverso é, contudo, admitir a influência em doenças como o cancro ou o SIDA, o que tem sido defendido nos últimos anos.

Estatísticas recentes, porém, mostram que, para estados clinicamente comparáveis, o tempo de vida de doentes cancerosos está relacionado com a atitude mental face à doença; por outro lado, a Academia das Ciências Médicas de Pequim está a obter resultados satisfatórios no reforço das capacidades imunológicas de portadores do SIDA, com ervas medicinais e práticas de respiração e concentração mental.

Num congresso da Associação Americana para o Avanço da Ciência, realizado nesta década, foram apresentadas comunicaçð̃es que sugerem que a atitude mental do doente portador do vírus do SIDA pode afectar a evolução desta doença.

No livro "Imagery in Healing", Jeanne Achterbery, professora e investigadora da Universidade do Texas, estabelece relaçð̃es entre imagens mentais e alteraçð̄es de estado físico e psíquico.

A herança cartesiana do dualismo corpo-espírito tem constituído um paradigma na Medicina contemporânea. Vários estudos actuais, contudo, sugerem que o corpo e o espírito interactuam e que os estados emocionais podem mesmo afectar o sistema imunológico. Pensa-se que o cérebro influencia a resposta do sistema imunológico às infecçð̃es, com hormonas e sinais nervosos, e que a actividade imunológica pode afectar o cérebro com hormonas aparentemente idênticas aos neurotransmissores cerebrais.

Apesar do cepticismo da Organização Mundial de Saúde, há quem acredite que o sistema imunológico pode vir a ser condicionado para prevenir e tratar doenças, que as emoçð̃es se relacionam com hormonas específicas e que o ser humano tem potencialmente, em si próprio, a capacidade de cura.
A Psiconeuroimunologia, ciência das relaçð̃es psicológicas, neurológicas e imunológicas, é um novo e esperançoso campo de investigação que utiliza as técnicas do Yoga como terapia.

A Psiconeuroimunologia é, para alguns, depois dos progressos da cirurgia e da descoberta da penicilina, considerada a $3 .^{\mathrm{a}}$ revolução da Medicina.

\section{Referências}

- De Rose, "Yoga Sutra de Pátañjali», ed. De Rose-Uniyoga, Rio de Janeiro, 1982

- "Yoga Today», ed. L. Randall, Sussex, Março e Outubro, 1987 - "Yoga», ed. A.V. Lysebeth, Bruxelas, Março-Abril, 1981, Setembro-Outubro, 1982

- «Corpo a Corpo", ed. C.S. Kai-Símbolo, 2, S. Paulo, 1989 - «Bushido», Ed. A.A.S. Oliveira, 1, Lisboa

- L. Brown, J. Howard, E.B. Barish, D. Gelman, M. Hager, G. Cowley, "Newsweek», ed. R.M. Smith, Nova York, Novembro, 1988

- G. Badou, «Diário de Notícias», Lisboa, 17 Novembro, 1988

- M.W. Browne, "Diário de Notícias», Lisboa, 25 Janeiro, 1989 - S. Rose, "A Química da Vida", ed. S. Rose-Ulisseia, Lisboa, 1973

- J.J.R. Fraústo da Silva, "Introdução à Química da Vida", ed. Univ. Nova de Lisboa, Monte da Caparica, 1985

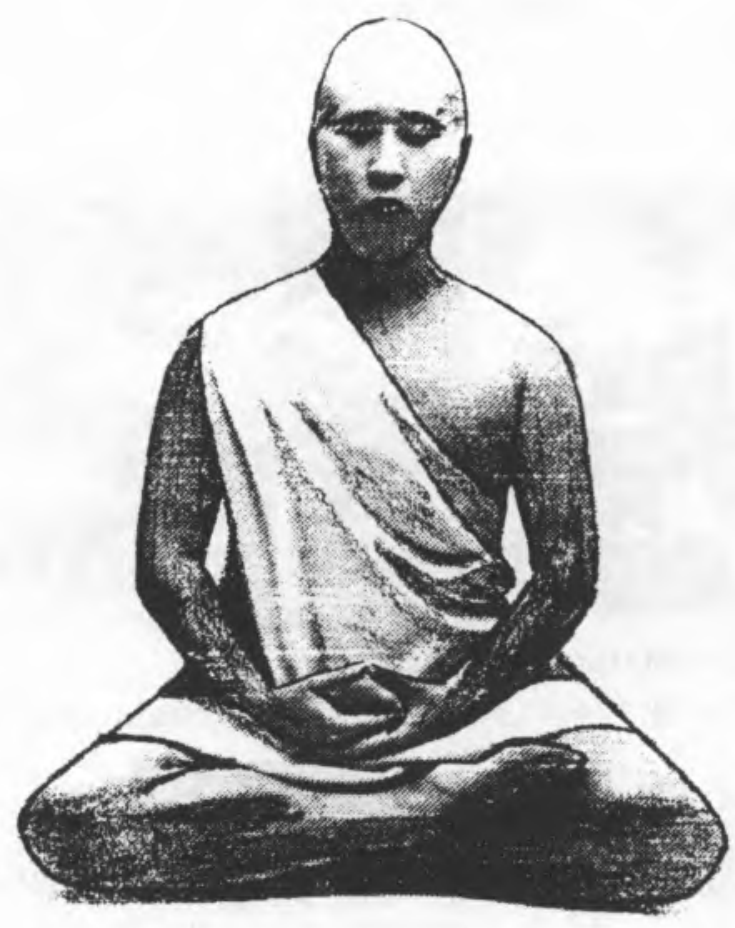




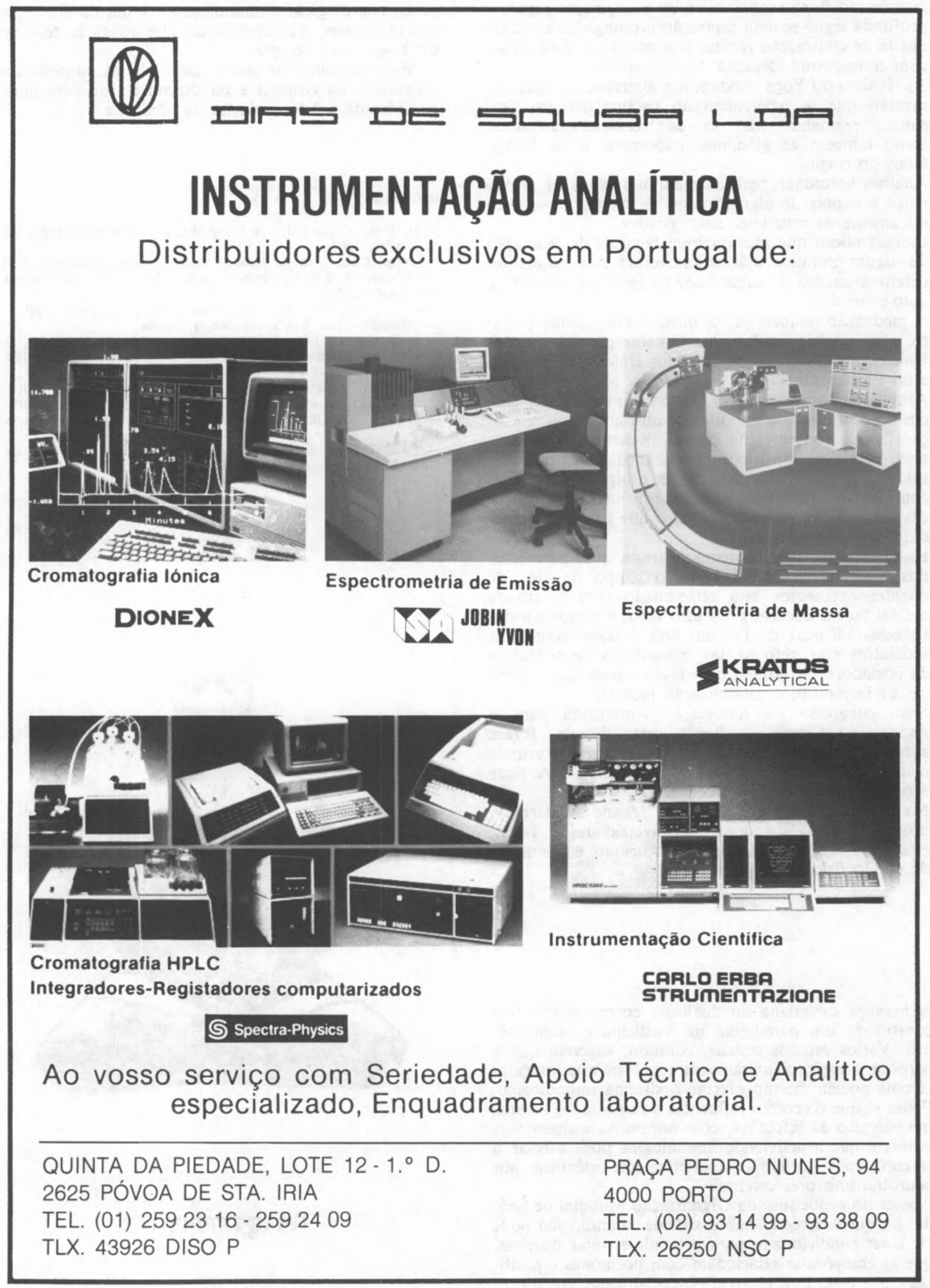

